\title{
ANALISIS PARAMETER SUMBER SPEKTRAL GEMPABUMI VTA (VULKANO TEKTONIK-A) TERHADAP AKTIVITAS VULKANIK GUNUNG SINABUNG
}

\author{
Tri Kusmita $^{1^{*}}$, Kirbani Brotopuspito ${ }^{2}$, Hetty Triastuty ${ }^{3}$ \\ ${ }^{1}$ Jurusan Fisika, Fakultas Teknik, Universitas Bangka Belitung, \\ Kampus Terpadu Balunijuk, Bangka, Kepulauan Bangka Belitung, Indonesia \\ ${ }^{2} J u r u s a n$ Fisika, Fakultas Matematika dan Ilmu Pengetahuan Alam, Universitas Gadjah Mada, \\ Sekip Utara, Bulaksumur, Yogyakarta, Indonesia \\ ${ }^{3}$ Pusat Vulkanologi dan Mitigasi Bencana Geologi Jl. Diponegoro No.57, Bandung, Indonesia \\ *e-mail : trikusmita@gmail.com
}

\begin{abstract}
ABSTRAK
Parameter sumber mendeskripsikan perbedaan physical properties volume seismik di bawah gunungapi. Parameter sumber dapat digunakan untuk membedakan kejadian seismik yang dibangkitkan oleh tipe aktivitas yang berbeda pada gunungapi. Perubahan sementara dari parameter sumber spektral dapat memberikan deskripsi tentang kejadian-kejadian utama selama proses erupsi terjadi. Parameter sumber dihitung dengan mengkorelasikan hubungan antara frekuensi sumber pada spektral pergeseran (frekuensi corner) dengan parameter sumber berdasarkan spektral sumber model Brune (1970). Frekuensi corner diperoleh dengan mengaplikasikan algoritma FFT pada spektral displacement VTA. Parameter sumber yang dianalisis dari gempabumi VTA ini diantaranya slop spektral, momen seismik, penurunan stress, panjang ruptur, momen magnitude dan energi radiasi. Berdasarkan nilai frekuensi corner yang diperoleh $(12 \mathrm{~Hz}-13 \mathrm{~Hz})$ diperoleh nilai momen seismik, momen magnitudo dan energi yang diradiasikan berturut-turut 0.2-1.9 x 10 $12 \mathrm{Nm}, 07-2 \mathrm{MW}$, dan 0,1-9,5 x $10^{15} \mathrm{erg}$. Panjang rupture memiliki range 144,2-243,1 m, slope spektral 2,1-7.8 dB/cm, dan stress drop 0.1-7,6 bar. Hasil-hasil tersebut mengarah pada kesimpulan bahwa perubahan karakteristik spektral dan nilai parameter sumber yang fluktuatif pada gempabumi VTA berasosiasi dengan perubahan aktivitas vulkanik dari gunung Sinabung.
\end{abstract}

Kata Kunci: Spektral; VTA; Parameter Sumber; Gempa Vulkanik

\begin{abstract}
[Title: Source Parameter Analysis of Deep Volcano Tectonic (Volcano Tectonic-A) Spectral on Volcanic Activities Mt. Sinabung] The source parameters describe the different physical properties of seismic volumes under the volcanoes. Source parameters that can be used to distinguish seismic events that are generated by different types of volcanoes activities. Temporary changes of the spectral source parameters provided a description of the main events during the eruption process. Source parameters are calculated by correlating the relationship between source frequency at spectral displacement (corner frequency) and source parameters based on spectral sources of the Brune model (1970). The angular frequency obtained by applying the FFT algorithm to the VTA spectral displacement. The source parameters analyzed from this VTA earthquake are the spectral slope, seismic moment, stress drop, length of rupture, moment magnitude and radiation energy. Based on the obtained corner frequency $(12 \mathrm{~Hz}-13 \mathrm{~Hz})$, seismic moment, moment magnitude and energy radiation respectively were at $0.2-1.9 \times 10^{12} \mathrm{Nm}, 0.7-2 \mathrm{Mw}$, and $0.1-9.5 \times 10^{15} \mathrm{erg}$. The length of rupture were from 144.2 to $243.1 \mathrm{~m}$, the spectra slope has $2.1-7.8 \mathrm{~dB} / \mathrm{cm}$, and stress drop are $0.1-7,6$ bar. From the results of this study, it can be concluded that the changes of spectra characteristic and fluctuate of source patrameters value of VTA earthquakes was asosiated with the different volcanic activity of Sinabung.
\end{abstract}

Keywords: Spectral; VTA; Source Parameter; Volcanic Earthquake

\section{PENDAHULUAN}

Parameter sumber dari gempabumi VT dianggap sebagai sinyal seismik yang berasal dari mekanisme kopel ganda (double couple mechanism), yang berasal dari sistem patahan atau retakan yang terjadi di dalam tubuh gunungapi (Nishimura \& Iguchi, 2011) Parameter sumber seperti ini telah dapat diprediksi dengan akurat, diantaranya hiposenter, mekanisme fokus hingga pola radiasi energi seismiknya (Nishimura \& Iguchi, 2011). 
Parameter sumber erat hubungannya dengan frekuensi spektral dari sinyal. Near dan far-field spectra yang terekam saat terjadinya gempabumi dapat mengindikasikan stres efektif yang berasal dari dalam tubuh gunungapi (Brune, 1970).

Salah satu gunungapi yang saat ini masih sangat aktif adalah gunung Sinabung. Gunung Sinabung merupakan gunungapi soliter yang memiliki puncak tunggal. Secara geologi gunungapi ini merupakan gunungapi muda yang masih dalam tahap pembentukan, dimana di bagian puncak ditemukan sumbat gunungapi yang menutupi kawah. Struktur sesar yang melewati gunung Sinabung adalah sesar strike slip mengiri berarah Baratdaya-Timurlaut. Terdapat sesar normal di daerah danau Kawar yang berada di sebelah Utara puncak gunung Sinabung dengan kelurusan topografi pada umumnya mengarah ke arah Baratdaya-Timurlaut. Struktrur puncak mengarah ke Baratlaut-Tenggara (Prambada, 2011).

Berdasarkan keadaan geologi tersebut kegempaan di gunung Sinabung didominasi oleh gempa VT. Gempa VT terutama VTA merupakan parameter utama yang digunakan dalam analisis spektral. Analisis spektral dilakukan untuk mendapatkan parameter sumber gunungapi. Parameter sumber ini berguna untuk mempelajari bagaimana dinamika sumber dari gempabumi VTA di gunung tersebut. Sumber gempabumi VTA diduga berasal dari retakan/getaran pada dinding kantong magma. Seiring mendekati erupsi, sumber gempabumi VTA terus naik kepermukaan dan berpusat pada dinding pipa kepundan (dike). Pada saat terjadinya erupsi sumber gempabumi aktivitas gempabumi VTA menurun dan didominasi oleh gempabumi-gempabumi vulkanik long periode (frekuensi rendah). Hal ini terjadi karena sumber gempabumi VT berada sangat dekat dari permukaan kawah. Sumber gempabumi VTA setelah erupsi akan kembali berpusat pada dinding pipa kepundan dan kantong magma. Tujuan dari penelitian ini adalah untuk mendapatkan parameter sumber berasarkan analisis spectral displacement yang diperoleh. Hal ini penting untuk mempelajari karakteristik gunung Sinabung lebih lanjut.

\section{METODE}

Secara umum metode yang digunakan pada penelitian ini adalah analisis kuantitatif. Data yang digunakan adalah data waveform dari gempabumi VTA dalam domain waktu yang terekam pada 4 PGA. Sinyal yang terekam di stasiun pengamat adalah spektral kecepatan. Untuk mendapatkan frekuensi sudut $\left(f_{\circ}\right)$ dan falt density level $\left(\Omega_{\odot}\right)$, spektral kecepatan harus dikonversi ke pergeseran
Untuk mendapatkan nilai frekuensi cutoff maksimum $\left(f_{\text {max }}\right)$ spektral kecepatan harus dikonversi ke spektral percepatan. Sebelumnya spektral terlebih dahulu di transformasi Fourier ke kawasan frekuensi (Kumar, dkk.,2012). Data domain waktu tersebut kemudian dilakukan koreksi baseline dan koreksi instrument dan windowing. Data yang telah diwindowing ditransformasikan ke dalam domain frekuensi menggunakan algoritma FFT berdasarkan model Brune untuk mendapatkan nilai frekuensi corner. Glassmoyer dan Borchedt (1990) menyatakan hubungan antara frekuensi sudut $\left(f_{0}\right)$ dan nilai spektral densitas yang konstan pada frekuensi rendah $\left(\Omega_{0}\right)$ diberikan oleh persamaan 1:

$$
f_{0}=\frac{1}{2 \pi} \sqrt{\frac{A_{\infty}}{\Omega_{0}}}
$$

Dengan mengasumsikan model sumber berbentuk lingkaran (Brune, 1970), jari-jari sumber ditentukan menggunakan persamaan (Brune, 1970 yang dikoreksi pada (Hank \& Wyss, 1972) untuk gelombang S dan untuk gelombang P (Hank, 1982) pada persamaan 2

$$
A(P)=\frac{2.34 \alpha}{2 \pi f_{0}(p)}
$$

$\alpha$ merupakan kecepatan gelombang $\mathrm{P}(\mathrm{km} / \mathrm{s})$, kecepatan disesuaikan dengan kedalamn sumber berdasarkan model kecepatan gunung Sinabung (Indrastuty, 2014), Hank \& Wyss (1972) mengasumsikan bahwa panjang rupture sama dengan diameter sumber sesar, maka panjang rupture dapat ditentukan dengan persamaan 3 :

$$
L=2 A \text {, }
$$

dengan $L$ adalah panjang rupture $(\mathrm{m})$.

Seismik momen diperoleh berdasarkan hubungan parameter sumber dengan flat spektral densitas spektral sumber $\left(\Omega_{0}\right)$, untuk gelombang $\mathrm{P}$ berdasarkan persamaan 4 (Keilis-Borok, 1960,)

$$
M_{0}(P)=\frac{\Omega_{0}(p)}{f^{P}} 4 \pi \rho A \alpha^{3} \quad 4
$$

$\Omega_{o}(P)$ flat spektral densitas (m).

Untuk menentukan besarnya penurunan stress digunakan persamaan 5:

$$
\Delta \sigma=\frac{7 M_{0}}{16 A^{3}}
$$

Momen magnitudo dapat juga ditentukan dari asimptot frekuensi rendah pada spektral pergeseran yang terkait secara fisik dengan pergeseran statik akhir (final static displacement) dari sebuah gempabumi. Momen magnitudo ditentukan menggunakan persamaan 6 (Hank, 1982): 


$$
M_{w}=\frac{2}{3}\left(\log M_{0}-9.1\right)
$$

Energi yang diradiasikan $\left(E_{R}\right)$ ketika terjadinya gempabumi bukanlah jumlah energi intrinsik gempabumi yang dipindahkan dari sumber. Energi yang diradiasikan hanyalah jumlah energi yang dipancarkan gempabumi akibat gelombang seismik. Bisa saja hanya merupakan sebuah fraksi kecil dari energi total yang dipindahkan selama proses terjadinya gempabumi [10]. $E_{R}$ ditentukan menggunakan hubungan antara frekuensi sudut dan flat spektral density (Hank \& Wyss, 1972), pada persamaan 7:

$$
E_{r}=\mathrm{k} \Omega_{0}{ }^{2} f_{0}{ }^{3}
$$

$k$ adalah konstanta. $k$ diestimasikan mempunyai nilai yang bergantung dengan tipe spektral. Brune memberikan nilai 0,37 untuk gelombang $\mathrm{S}$ dan 0.50 untuk gelombang P.

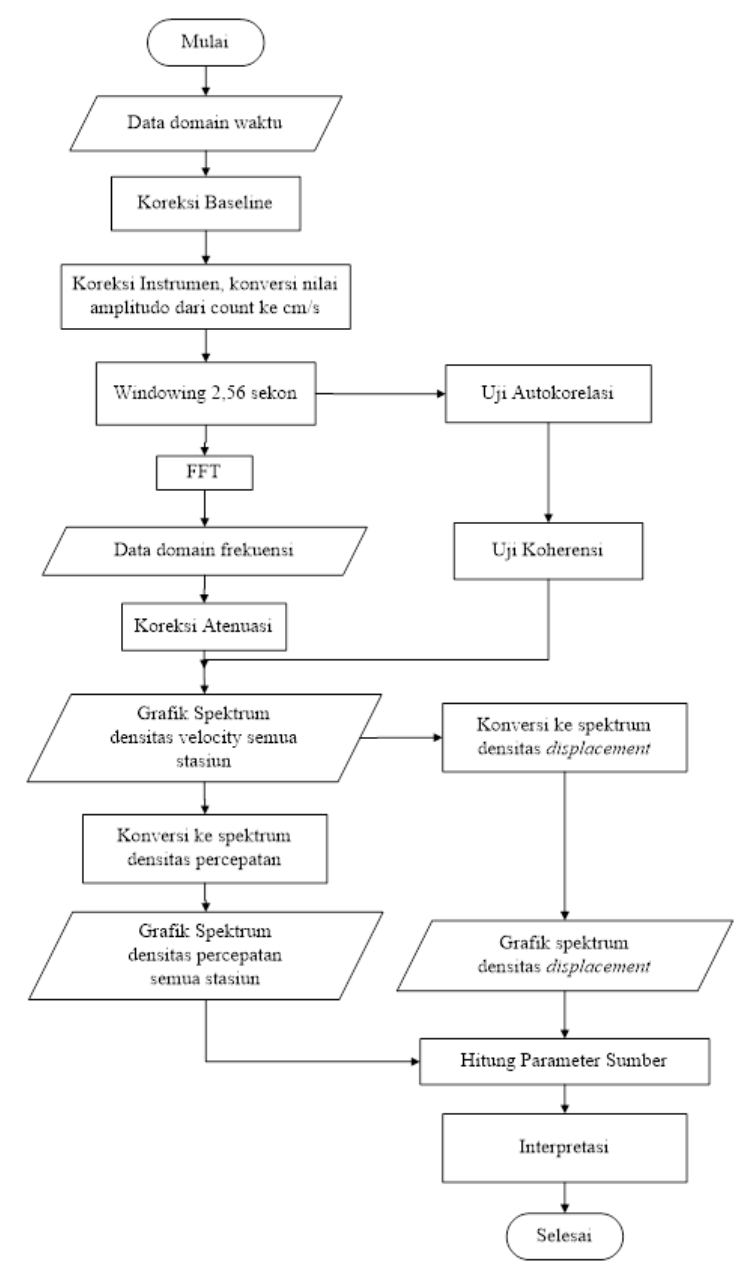

Gambar 1. Diagram alir Penelitian

Sebelumnya spekral dalam domain frekuensi terlebih dahulu dilakukan uji autokorelasi dan koherensi dan koreksi atenuasi untuk mendapatkan hasil yang lebih akurat. Diagram alir penelitian ditampilkan pada gambar 1.

\section{HASIL DAN PEMBAHASAN}

Spektral gempabumi vulkanik secara umum dapat digunakan untuk 2 tipe aplikasi. Spektral total dari rekaman seismik digunakan untuk klasifikasi gempabumi vulkanik dan juga monitoring aktivitas seismik. Spektral gelombang badan dan gelombang permukaan digunakan untuk studi parameter sumber dari gempabumi vulkanik (Zobin, dkk., 2010). Perhitungan parameter sumber dilakukan dengan mengasumsikan kecepatan perlapisan sebanyak 6 lapisan kecepatan secara vertikal dengan asumsi bahwa lapisan tersebuh homogen secara horizontal (Indrastuty, 2014), Densitas batuan yang digunakan sebesar $2.36 \mathrm{gr} / \mathrm{cm}^{3}$ (mengacu pada densitas batuan gunung Merapi, Jawa Tengah).

Sebaran frekuensi sudut gunung Sinabung periode Juli-November 2013 dituangkan pada Gambar 2. Frekuensi sudut, erat hubungannya dengan dimensi sumber dari gempa VTA. Dimensi sumber yang dimaksud adalah panjang rupture sesar yang dihasilkan ketika terjadinya erupsi. Frekuensi sudut gunung Sinabung berada pada rentang nilai 10,2-13,7 Hz, sebagian besar didominasi oleh frekuensi 12-13 Hz. Frekuensi sudut sebelum terjadinya erupsi memiliki frekuensi yang relatif lebih besar dibandingkan dengan frekuensi sudut setelah terjadinya erupsi. Hal ini berkaitan erat dengan panjang rupture yang terbentuk ketika sebelum dan setelah terjadinya erupsi memiliki panjang yang berbeda.

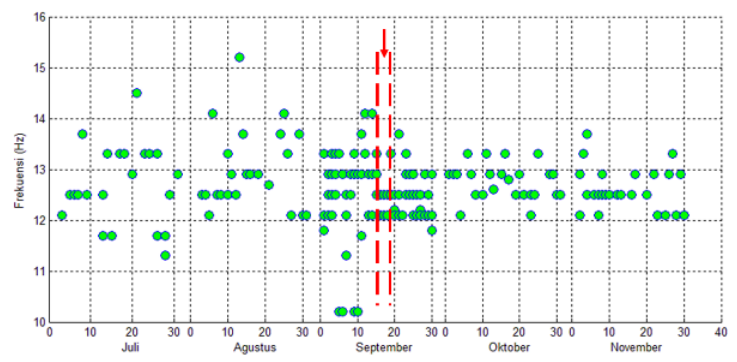

Gambar 2. Frekuensi sudut gempabumi VTA gunung Sinabung periode Juli-November 2013 garis merah adalah garis batas sebelum dan setelah erupsi, daerah yang ditunjukkan tanda panah merah adalah saat terjadinya erupsi (Brotopuspito, dkk., 2018).

Panjang rupture diperoleh berdasarkan panjang jari-jari dislokasi lingkaran model Brune, 1970. Selama periode Juli-November 2013, panjang rupture gunung sinabung adalah sebesar 144,2-243,1 $\mathrm{m}$. Sebagian besar kejadian gempabumi mempunyai panjang rupture 180-210 m (Gambar 3). 


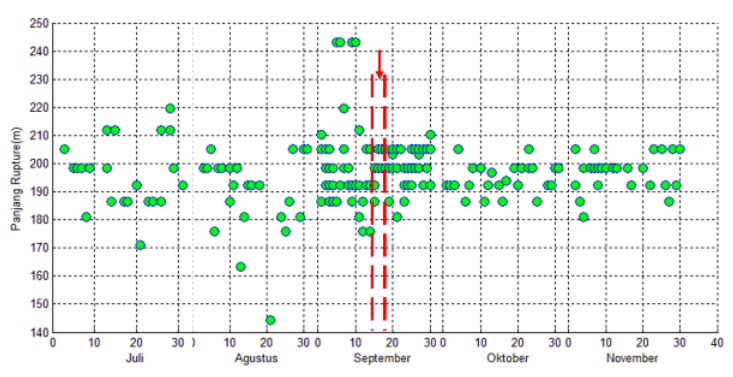

Gambar 3. Panjang rupture gempabumi VTA gunung Sinabung periode Juli-November 2013, garis merah adalah garis batas sebelum dan setelah erupsi, daerah yang ditunjukkan tanda panah merah adalah saat terjadinya erupsi

Jumlah radiasi dari gempabumi vulkanik dapat diekpresikan dengan jumlah seismik momen. Seismik momen kemungkinan berhubungan dengan perbedaan formasi dari sumber gempabumi vulkanik untuk tipe erupsi yang berbeda. Seismik momen gunung Sinabung pada periode Juli-November 2013 secara keseluruhan berada 0.2-1.9 x $10^{12} \mathrm{Nm}$ (Gambar 12). Namun, sebagian besar momen seismik berada pada 0.2-1 x 10 $12 \mathrm{Nm}$ (Gambar 4).

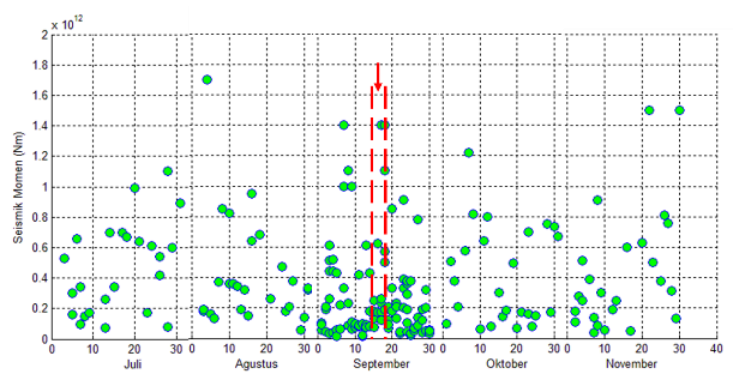

Gambar 4. Seismik momen gempabumi VTA gunung Sinabung periode Juli-November 2013 garis merah adalah garis batas sebelum dan setelah erupsi, daerah yang ditunjukkan tanda panah merah adalah saat terjadinya erupsi.

Energi yang diradiasikan oleh sumber pada setiap kejadian gempabumi VTA bukan merupakan energi total yang dilepaskan selama terjadinya gempabumi, melainkan energi dari fragmen terkecil dari rupture. Energi yang diradiasikan oleh gempabumi VTA di gunung Sinabung secara keseluruhan sebesar 0,1-9,5 x 10 ${ }^{15}$ erg (Gambar 5 ).

Energi juga dapat diekpresikan dalam bentuk kekuatan gempabumi vulkanik yang dapat ditinjau dari besarnya magnitudo momen dari setiap kejadian VTA. Gempabumi VTA yang terekam di stasiunstasiun di sekitar puncak gunung Sinabung tergolong relatif kecil, yaitu 0.7-2.1 Mw (Gambar 6).

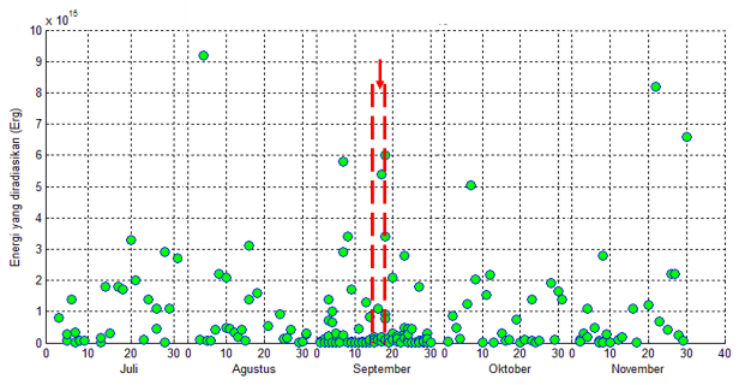

Gambar 5. Energi seismik yang diradiasikan gempabumi VTA gunung Sinabung periode Juli-November 2013, garis merah adalah garis batas sebelum dan setelah erupsi, daerah yang ditunjukkan tanda panah merah adalah saat terjadinya erupsi

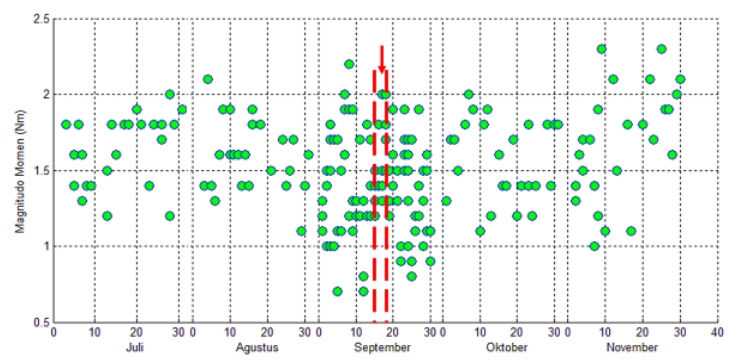

Gambar 6. Magnitudo momen gempabumi VTA gunung Sinabung periode Juli-November 2013, garis merah adalah garis batas sebelum dan setelah erupsi, daerah yang ditunjukkan tanda panah merah adalah saat terjadinya erupsi

Aktivitas vulkanik gempabumi Sinabung juga dapat diamati dari parameter sumber lainnya yaitu stress drop dan kecepatan slip spektral. Kecepatan slip rupture direpresentasikan melalui besarnya slope spektral VTA. Slope VTA dihitung dari kemiringan spektral yang terekam dalam kawasan amplitudo displacement. Slope spektral dapat merepresentasikan kecepatan kerak ketika dimulai terjadinya retakan/rekahan hingga akhirnya benarbenar patah. Diasumsikan semakain besar slope spektral, maka semakin besar kecepatan dari rupture tersebut. Gambar 6 menunjukkan besarnya kemiringan spektral pergeseran gunung Sinabung periode Juli-November 2013. Kemiringan spektral secara keseluruhan berada pada 2,1-7.8 dB/cm. Sebagian besar tersebar dengan kemiringan slope 2-5 $\mathrm{dB} / \mathrm{cm}$ (Gambar 7).

Kemiringan spektral cukup tinggi pada tanggal 5 September, yaitu 7,1 dB/cm. Kemudian pada tanggal 12 dan 22 September berturut-turut 7.2 dan $7.7 \mathrm{~dB} / \mathrm{cm}$. Peningkatan yang cukup signifikan dibandingkan dengan kemiringan spekral lainnnya diinterpreasikan dengan adanya rekahan/patahan yang cukup besar dikerak bumi di 
bawah permukaan tubuh gunungapi. Hal ini didukung dengan tingginya nilai frekuensi corner pada tanggal tersebut (Gambar 2) . Pada 5 September sebesar 23,3 Hz, 12 September $26,2 \mathrm{~Hz}$ dan 22 September 26,5 Hz. Hank (1982) menjelaskan bahwa frekuensi cutoff maksimum dari spektral densitas pergeseran berhubungan erat dengan site effect dari sumber. Site effect yang dimaksud disini adalah perubahan geologi dari sumber karena adanya suatu kejadian yang akhirnya mengakibatkan struktur batuan ataupun kerak bumi yang awalnya kerak menjadi lunak. Hal tersebut bisa saja diakibatkan patahnya, atau retaknya struktur batuan ketika terjadinya aktivitas magmatik yang cukup besar.

Variasi sementara dari stress drop gempabumi VT yang berbeda dipelajari berhubungan dengan deformasi kerak bumi di bawah tubuh gunungapi. Zobin (2010) menghubungkan gempabumi dengan HSD (High Stress Drop) sebagai kemungkinan dari produk rekahan dari batuan induk yang terjadi karena adanya panas magmatik. Secara relatif, pada LSD (Low Stress Drop) rekahan mungkin disebabkan oleh slip di sepanjang rekahan yang sudah ada sebelumnya dan kembali terbentuk karena adanya kejadian gempabumi besar selama gerakan magma.

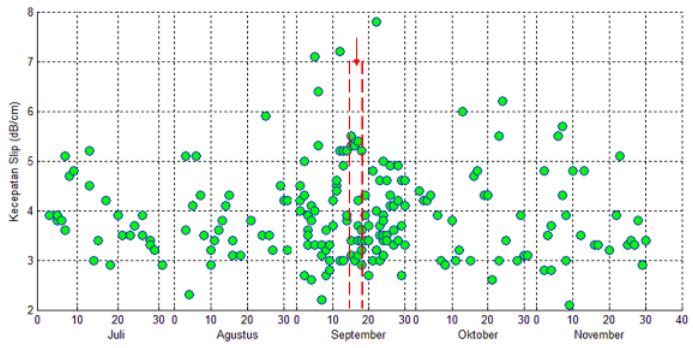

Gambar 7. Kemiringan spektral pergeseran gempabumi VTA gunung Sinabung periode Juli-November 2013, garis merah adalah garis batas sebelum dan setelah erupsi, daerah yang ditunjukkan tanda panah merah adalah saat terjadinya erupsi

Stress drop gunung Sinabung pada periode JuliNovember 2013 adalah sebesar 0.1-7,6 bar (Gambar 8). Sebagian besar kejadian gempabumi VTA memiliki stress drop sebesar 0.1-5 bar.

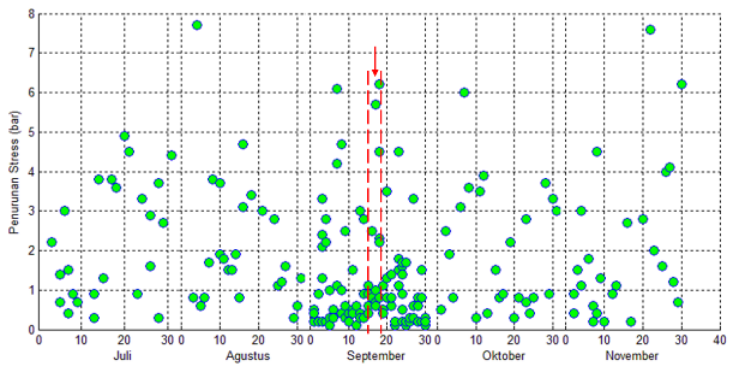

Gambar 8. Penurunan Stress gempabumi VTA gunung Sinabung periode Juli-November 2013, garis merah adalah garis batas sebelum dan setelah erupsi, daerah yang ditunjukkan tanda panah merah adalah saat terjadinya erupsi

\section{KESIMPULAN DAN SARAN}

Parameter sumber mampu mendeskripsikan perbedaan physical properties dari volume seismik di bawah gunungapi. Parameter sumber dapat digunakan untuk membedakan kejadian seismik yang dibangkitkan oleh tipe aktivitas yang berbeda pada gunungapi. Perubahan sementara dari parameter sumber spektral dapat memberikan deskripsi tentang kejadian-kejadian utama selama proses erupsi terjadi. Berdasarkan hasil yang diperoleh maka dapat disimpulkan bahwa panjang ruptur dan kecepatan slop mengalami peningkat sebelum terjadinya radiasi. Kedua parameter ini berasosiasi dengan pengumpulan energi. Momen seismik, momen magnitudo dan energi radiasi meningkat saat erupsi dan setelah terjadinya erupsi. Ketiga parameter tersebut berasosiasi dengan pelepasan energi.

Penelitan lebih lanjut, dapat dibuat sebuah model sumber bawah permukaan gunung Sinabung, untuk mendapatkan informasi tentang posisi, bentuk dan ukuran kantong magma.

\section{DAFTAR PUSTAKA}

Brotopuspito, K., Kusmita, T. Dan Triastuty, H., 2018, Spectra Analysis For Source Dynamic Identification Of Deep Volcano Tectonic Underneath Mounth Sinabung, North Sumatera, Conference Proceeding, EAGEHAGI 1st Asia Pacific Meeting On Near Surface Geoscience And Engineering, Yogyakarta.

Brune, J. N., 1970, Tectonic Stress and Spectra of Seismic Shear Waves from Earthquakes, Journal of Geophysical Research, Vol. 7

Glassmoyer, G. \& Borchertdt, 1990, Source Parameters and effect of Bandwith and Local Geology on High-Frequency Ground Motions Observed for Aftershock of the Northeastern Ohio earthquake of 31 Jnury 1986, Bulletin of the Seismological Society of America, Vol.80.

Hank, T. C., 1982, Fmax, Bulletin of the seismological Society of America, Vol. 72.

Hank, T. C., \& Wyss, M., 1972, The Use of Body Wave Spectra in the Determination of Seismic Source Parameters, Bulletin of the seismological Society of America, Vol. 62. 
Indrastuty, N., 2014, Studi Kegempaan Seismik Tomografi Gunung Sinabung, Tesis, ITB, Bandung.

Keilis-Borok, V. I., 1960, Investigation of Mechanism of earthquakes, Sov, Res, Geophysics.

Kumar, A., Ashwani, K., Himashu, M., Ashok, K., Rakhi, B., 2012, Sotfware to Estimate Earthquake Spectral and Source Parameters, International Journal of Geosciences.

Nishimura, T., \& Iguchi, M., (2011), Volcanic Earthquakes and Tremor in Japan. Kyoto, Kyoto University Press.

Prambada, O., 2011, Pemetaan Geologi G. Sinabung, Pusat Vulkanologi dan Mitigasi Bencana Geologi, Kementerian Energi dan Sumber Daya Mineral.

Zobin, V.M., Melnik, O.E., Gonzalez, M., Macedo, O., and Breto'n, M. (2010). Swarms of micro-earthquakes associated with the 2005 Vulcanian explosion sequence at Volca'n de Colima, Me'xico. Geophys. J. Int. 182 